\title{
Plexiform Unicystic Ameloblastoma in a 12-Year-Old Child - An Unusual Case Report
}

\author{
Sunitha Manikantan ${ }^{1}$, Rajesh Ramankutty²
}

\begin{abstract}
${ }^{1}$ Professor and HOD, Department of Oral Medicine and Radiology, Noorul Islam College of Dental Sciences, NIMS Medicity, Aralummoodu, Thriruvananthapuram, Kerala, India. ${ }^{2}$ Professor and HOD, Department of Paediatric and Preventive Dentistry, Indira Gandhi Dental College, Kothamangalam, Ernakulam, Kerala, India.
\end{abstract}

\section{INTRODUCTION}

Ameloblastoma is the most common tumour of odontogenic origin accounting for $1 \%$ of all tumours in the head and neck region and around $11 \%$ of all odontogenic tumours.[1] The World health Organization (1991) defined ameloblastoma as a benign but locally aggressive tumour with a high tendency to recur. It consists of proliferating odontogenic epithelium lying in a fibrous stroma. ${ }^{[2]}$ Three main clinical subtypes of ameloblastoma exist namely, unicystic, multicystic and peripheral.[3] Multicystic is the most common type and represents $86 \%$ of cases. Peripheral tumours occur solely in the soft tissues without involving the bone especially in the gingiva of mandibular premolar region accounting for $2 \%$ of all ameloblastomas. ${ }^{[4]}$ Unicystic ameloblastomas represent $6 \%$ of cases and has been variously referred to as mural ameloblastomas, luminal ameloblastomas and ameloblastomas arising in dentigerous cyst. [5] Unicystic ameloblastomas (UCA) commonly occur in the $2^{\text {nd }}$ or $3^{\text {rd }}$ decade of life encountered asymptomatically in the posterior region of mandible.[6] UCA has less aggressive biologic behaviour and lower recurrence rate than multicystic ameloblstoma.[7]

Ameloblastoma is a benign tumour of odontogenic origin which usually occurs in the middle age group and is rare in children. Of all ameloblastomas in younger patients, unicystic ameloblastoma represents $6 \%$ of the cases. Plexiform unicystic ameloblastoma refers to a pattern of epithelial proliferation that has been described in dentigerous cysts, primarily in persons in the $2^{\text {nd }}$ and $3^{\text {rd }}$ decade of life predominantly in the posterior part of mandible. Unicystic ameloblastoma exhibits clinical and radiographic features of an odontogenic cyst but on histological examination shows a typical ameloblastomatous epithelium lining part of cyst cavity with or without luminal or mural proliferation. A conservative surgical approach is usually followed. A case of plexiform unicystic ameloblastoma in a 12 year old child who presented with an unusual soft tissue proliferative mass is discussed in this article.

\section{PRESENTATION OF CASE}

A 12-year-old boy reported to the dental O.P.D. with complaint of a swelling on the lower left back tooth region since 1 month which slowly enlarged to the present size. He gave a history of traumatising the swelling and that a part of the tissue got worn out during tooth brushing. Extra oral examination showed that the sub mandibular lymph nodes were enlarged and non tender. There was no facial asymmetry. On intraoral examination, a localised proliferative growth of size $3 \times 2 \mathrm{~cm}$ was noted on the left mandibular alveolar ridge partially covering the crown of 37 and extending to the retromolar area. (Fig. 1) The surface appeared granular and was covered with a yellowish slough. It was soft in consistency and slightly tender on palpation. Cortical expansion was noted on the lingual aspect. Correlating the history and clinical features a provisional diagnosis of dentigerous cyst was made. Differential diagnosis included peripheral giant cell granuloma, pyogenic granuloma and unicystic ameloblastoma.
Corresponding Author:

Dr. Sunitha Manikantan,

Thrayambakam, T. C. 10/852(5),

Edakulam-Mannamoola Road,

Peroorkada, P. O., Thiruvananthapuram-5 Kerala, India.

E-mail: sunitham7373@gmail.com

DOI: 10.14260/jemds/2019/602

Financial or Other Competing Interests: None.

How to Cite This Article:

Manikantan S, Ramankutty R. Plexiform unicystic ameloblastoma in a 12 year old child- an unusual case report. J. Evolution Med. Dent. Sci. 2019;8(35):2775-2777, DOI: 10.14260/jemds/2019/602

Submission 10-06-2019,

Peer Review 14-08-2019,

Acceptance 20-08-2019,

Published 02-09-2019. 
Intra oral periapical radiograph showed a unilocular radiolucency surrounding the crown of impacted 38 impinging on the crown of 37 . Panoramic radiograph showed a welldefined circum-coronal radiolucency of size $3 \times 3 \mathrm{~cm}$ with corticated borders surrounding the crown of impacted 38 and extending from the distal aspect of 37 up to $1 \mathrm{~cm}$. into the ramus of mandible. (Fig. 2) CT mandible showed an expansile lytic lesion in the mandible in relation to the crown of unerupted 38 with enhancing soft tissue areas within and with lingual cortex thinned out suggestive of dentigerous cyst with Ameloblastoma- mural type. (Fig. 3) Biopsy was done and histopathological examination showed a cystic space lined by tall columnar epithelium and proliferating odontogenic epithelial cells in the form of interconnecting strands into the lumen. Moderate amount of vascularity with formed blood vessels was noted in the connective tissue stroma suggestive of plexiform unicystic ameloblastoma. Surgical resection of the tumour was done under general anaesthesia and postoperatively an obturator was fabricated over the surgical site to facilitate healing. The patient was followed up and showed complete healing after 2 months (Fig. 4)

\section{DISCUSSION}

The concept of unicystic ameloblastoma was first introduced by Robinson and Martinez in 1977 [8]. They occur intraosseously in the jaws, more commonly in the mandibular molar and ascending ramus region. UCA is seen to occur in younger individuals with the 16-20 year age group being most commonly involved and are seen rarely in patients over 40 years of age. Our case exhibits all the above features regarding the age and site of predilection. The most common presentation is swelling of the jaw associated with an impacted third molar (Dentigerous type) or sometimes without a relationship to teeth (Non dentigerous type). Our case presented with a swelling of the jaw with lingual cortical expansion but was peculiar in that it was associated with a proliferative soft tissue granulomatous lesion. Proliferation of tumour through the alveolar bone could be explained as the basis for such a clinical appearance

Radiographic appearance is similar to that of a dentigerous cyst with a well circumscribed radiolucency associated with the crown of a tooth. In our case the tumour was associated with an impacted mandibular third molar and presented features consistent with findings in the literature. Ackermann et al classified this entity into 3 histologic groups Group 1luminal unicystic ameloblastoma consisting of a unilocular cyst lined by epithelium that in some areas shows ameloblastic transformation without infiltration into the connective tissue wall, Group 2- Intraluminal/plexiform unicystic ameloblastoma consisting of a unilocular cyst with the lining epithelium showing a nodular proliferation into the lumen without infiltration into the connective tissue, Group 3- mural unicystic ameloblastoma with invasive islands of ameloblastomatous epithelium in the connective tissue wall that may or may not be connected to the cyst lining epithelium. [9] Our case showed the features of intraluminal plexiform type and can be categorised in Group 2. In case of intraluminal plexiform type enucleation is the standard treatment protocol when the ameloblastic elements are confined to the lumen of the cyst without penetration into the fibrous tissue capsule. Local resection is indicated if specimen shows a mural component with extension into the fibrous cyst wall. The age of the patient is another influencing factor related to the choice of treatment. As UCA tends to affect young adolescent patients, care is taken to minimise surgical trauma and permit tooth development and jaw function to proceed reasonably unimpaired. Late recurrence following treatment is commonly seen, the average interval being 7 years. Recurrence is also related to the histological subtypes with those invading the fibrous wall with a rate of $35.7 \%$ and others at a rate of $6.7 \%$.[10]
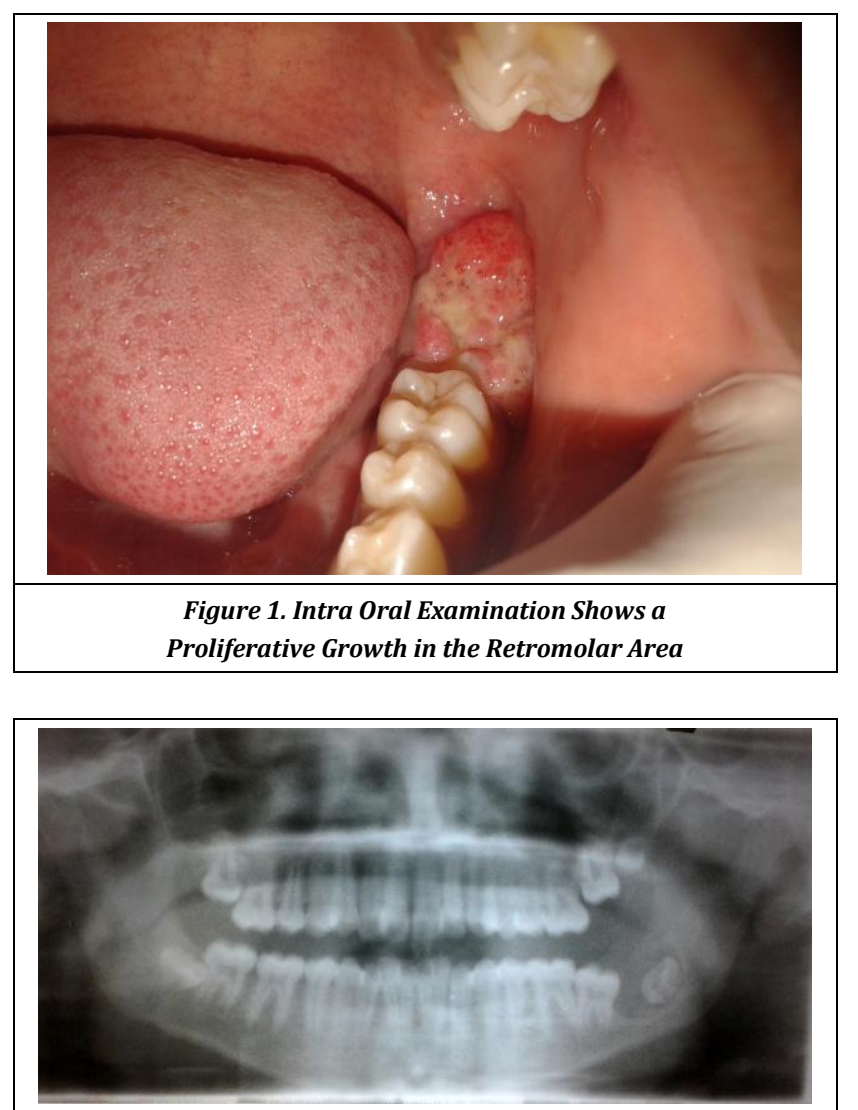

Figure 2. Panoramic X-Ray Shows a unilocular Circum-Corona Radiolucency in Relation to Impacted 38

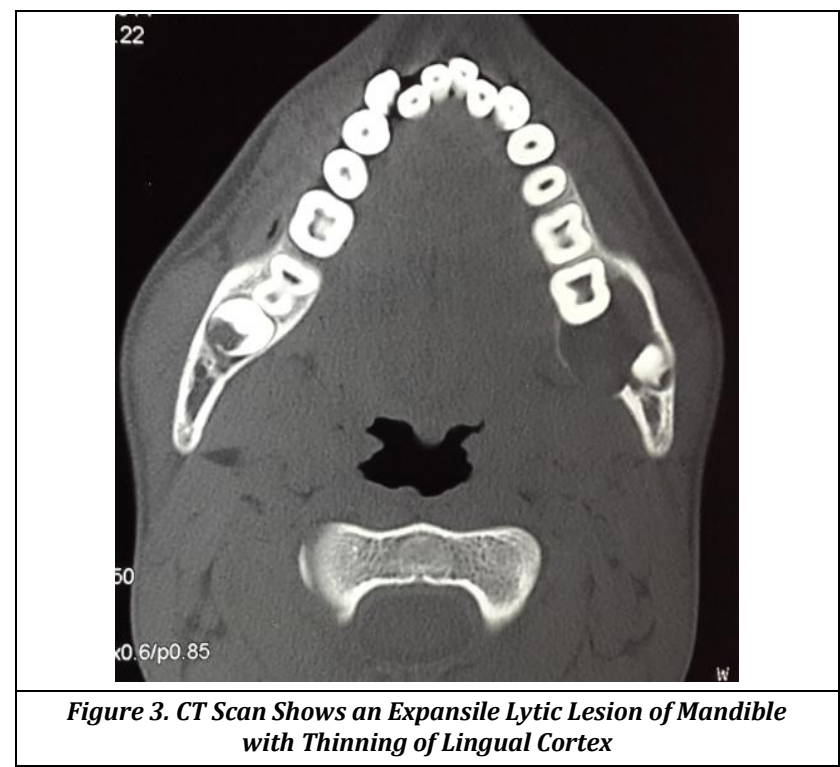




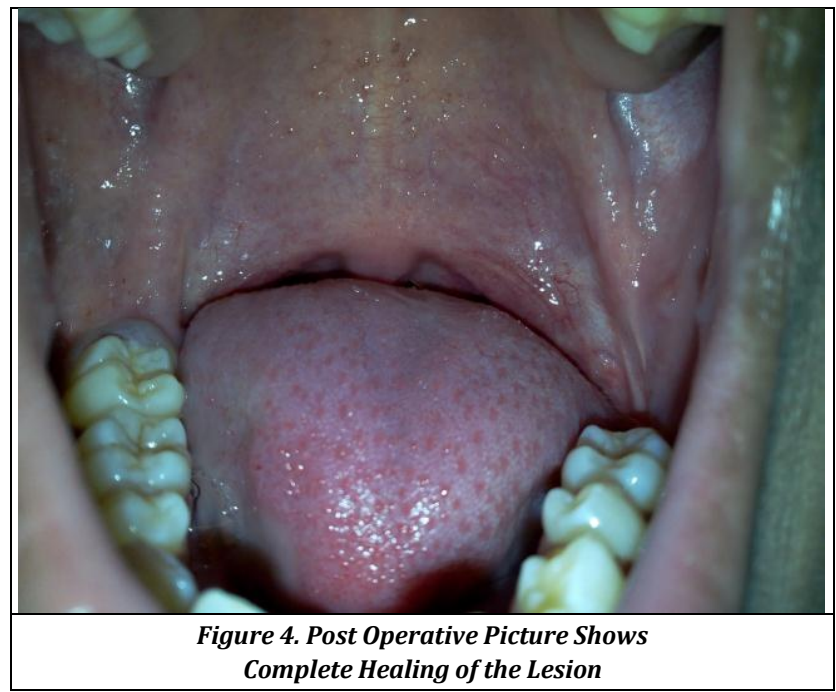

\section{CONCLUSION}

Unicystic ameloblastoma is characterised by specific clinical and histopathological features. The clinician should be aware of the unusual presentation of this neoplasm and include this in the differential diagnosis of any such lesion occurring in the posterior mandible in a young patient. A careful histopathological diagnosis goes a long way in the management of these lesions effectively. The relatively young age of occurrence poses a challenge to the surgeon in the surgical management of this tumour. As recurrence is long delayed a long term follow up is mandatory. More insights regarding the tumour markers specific for ameloblastoma can cause a drastic change in the approach toward the tumours

\section{REFERENCES}

[1] Williams TP. Management of ameloblastoma: a changing perspective. J Oral Maxillofac Surg 1993;51(10):1064-70.
[2] Kramer IRH, Pindborg JJ, Shear M. Histological typing of odontogenic tumours. WHO International Histological Classificatin of Tumours. $2^{\text {nd }}$ edn. Berlin: Springer-Verlag 1992: p. 11-4.

[3] Reichart PA, Philipsen HP. Classification of odontogenic tumours and allied lesions. Quintessence Publishing Co. Ltd., 2004: p. 21-3.

[4] Reichart PA, Philipsen HP, Sonner S. Ameloblastoma: biological profile of 3677 cases. Eur J Cancer B Oral Oncol 1995;31B(2):86-99.

[5] Chana JS, Chang YM, Wei FC, et al. Segmental mandibulectomy and immediate free fibula osteosepto cutaneous flap reconstruction with endosteal implants: an ideal treatment method for mandibular ameloblastoma. Plast Reconstr Surg 2004;113(1):80-7.

[6] Heikinheimo K, Jee KJ, Niini T, et al. Gene expression profiling of ameloblastoma and human tooth germ by means of a cDNA microarray. J Dent Res 2002;81(8):52530.

[7] Olaitan AA, Adekeye EO. Unicystic ameloblastoma of the mandible: a long-term follow-up. J Oral Maxillofac Surg 1997;55(4):345-50.

[8] Robinson L, Martinez MG. Unicystic Ameloblastoma: a prognostically distinct entity. Cancer 1977;40(5):227885.

[9] Ackerman GI, Altini M, Shear M. The unicystic ameloblastoma: a clinicopathologic study of 57 cases. J Oral Pathol 1988;17(9-10):541-6.

[10] $\mathrm{Li} \mathrm{T}, \mathrm{Wu} \mathrm{Y,} \mathrm{Yu} \mathrm{S}$, et al. Clinicopathologic features of unicystic ameloblastoma with special reference to its recurrence. Zhonghua Kou Qiang Yi Xue Za Zhi 2002;37(3):210-12. 